\title{
Does Parental Involvement Matter for Student Achievement and Mental Health in High School?
}

\author{
Ming-Te Wang \\ University of Pittsburgh
}

\author{
Salam Sheikh-Khalil \\ University of Michigan
}

\begin{abstract}
Parental involvement in education remains important for facilitating positive youth development. This study conceptualized parental involvement as a multidimensional construct-including school-based involvement, home-based involvement, and academic socialization-and examined the effects of different types of parental involvement in 10th grade on student achievement and depression in 11th grade (approximately ages 1517 years). In addition, this study tested whether parental involvement influenced adolescent outcomes by increasing their academic engagement in school. A total of 1,056 adolescents participated in the study (51\% males; 53\% European American, 40\% African American, and 7\% other). Parental involvement was found to improve academic and emotional functioning among adolescents. In addition, parental involvement predicted adolescent academic success and mental health both directly and indirectly through behavioral and emotional engagement.
\end{abstract}

Enhancing the academic achievement and mental health of students is an important educational goal. To achieve this, it is essential to identify the contextual factors that influence academic and emotional functioning and the pathways through which they operate. Numerous studies have identified parental involvement in education as an important way to facilitate positive youth development (Epstein \& Sanders, 2002; Hill \& Taylor, 2004; Jeynes, 2009; Seginer, 2006). In addition to promoting academic success, parental involvement in education may serve as a critical context for the development of adolescent mental health (Roeser \& Eccles, 2000; Wang, Brinkworth, \& Eccles, 2013). In fact, a number of studies have highlighted the importance of parental behaviors in the etiology of depression during adolescence (Duchesne, Ratelle, Poitras, \& Drouin, 2009; Pomerantz, Moorman, \& Litwack, 2007). Research has also shown that enhanced emotional behaviors can have a positive impact on school success and ultimately in life (Masten et al., 2005). However, most extant research on the effect of parental involvement in education has focused on academic outcomes, with less emphasis on its potential impacts on emotional functioning in adolescents. Given that adolescents' mental health is integral to their academic competence, a deeper understanding of the associations between parental

Correspondence concerning this article should be addressed to Ming-Te Wang, 230 South Bouquet Street, Pittsburgh, PA 15260. Electronic mail may be sent to mtwang@pitt.edu. involvement, academic achievement, and adolescent mental health is needed.

Researchers have conceptualized parental involvement in secondary school as a multidimensional construct, including involvement at school, involvement at home, and academic socialization (Hill \& Tyson, 2009). Unfortunately, most empirical studies have not investigated how and to what extent each form of parental involvement is positively or negatively related to achievement and mental health. The most effective types of involvement for promoting healthy adolescent development in high school have not been identified. This makes it difficult for researchers and practitioners to draw lessons from the literature when designing programs for parental involvement with high school students. Moreover, we know very little about the underlying mechanisms that explain variations in effectiveness of parental involvement on achievement or mental health. Previous research has shown academic engagement as a strong predictor of academic and emotional development (Li \& Lerner, 2011; Wang \& Holcombe, 2010). Academic engagement is malleable to contextual characteristics, thus making it a critical target for interventions aimed at promoting healthy adolescent development. Although studied less often, it is

(C) 2013 The Authors

Child Development (c) 2013 Society for Research in Child Development, Inc. All rights reserved. 0009-3920/2014/8502-0019

DOI: $10.1111 /$ cdev. 12153 
possible that parental involvement may play an important role in both sustaining student academic achievement and enhancing mental health through its impact on student academic engagement.

The aims of this study were thus to extend previous research by examining (a) the effects of different types of parental involvement on high school student academic achievement and depression, (b) the mediating role of academic engagement in the association between parental involvement and adolescent outcomes, and (c) whether these associations vary by ethnicity and socioeconomic status (SES). Specifically, we seek to identify the extent to which parental involvement in education promotes student achievement and mental health and to understand whether parental involvement influences student achievement and mental health by increasing their academic engagement in high school. The study of parental involvement as a multidimensional construct will help to identify the particular parental involvement strategies that foster academic and emotional functioning in high school and advance our understanding of the mechanisms through which they operate. Such contributions to the knowledge base are critical to informing effective parent involvement programs.

\section{Theoretical and Empirical Framework}

Parental involvement in education can be defined as "parents' interaction with schools and with their children to benefit their children's educational success" (Hill et al., 2004). Researchers have conceptualized parental involvement as a multifaceted construct encompassing involvement at school, involvement at home, and academic socialization (Epstein \& Sanders, 2002; Fan \& Chen, 2001; Hill \& Tyson, 2009). School-based involvement includes parent-teacher communication, attendance at school events, and volunteering at school. Home-based involvement includes provision of structure for homework time and leisure time (e.g., having a set time or location to do homework, visiting museums), as well as monitoring of schoolwork and progress. Academic socialization refers to the communication of parental expectations about schoolwork and the importance of education, encouragement of educational and career goals, and making plans and preparations with adolescents that support their future goals.

Self-system theory (Skinner, Kindermann, Connell, \& Wellborn, 2009), a motivational framework grounded in self-determination theory (Ryan \& Deci, 2000), was used to understand how both the home and school environments interact to influence adolescent academic and emotional functioning. Self-system theory is a mediational model linking contextual characteristics to patterns of action (e.g., engagement vs. disengagement) through an individual's appraisals of how competent, autonomous, and related he or she feels within particular contexts (Connell \& Wellborn, 1991). Drawing on this theoretical framework, parents create opportunities for adolescents to engage in a variety of educational activities (Skinner \& Wellborn, 1994). The experiential quality of the activity and interaction with parents provides adolescents with information about themselves as being competent to succeed, as being autonomous learners, as being related to others in these settings, and as having opportunities to fulfill their personal goals. This information cumulates to influence adolescents' engagement across various educational activities and throughout their future development. As such, parenting practices that fulfill adolescents' psychological needs of competence, autonomy, and relatedness increase school engagement, which in turn promotes positive adolescent outcomes (Eccles et al., 1993; Skinner \& Wellborn, 1994). Conversely, parenting practices that conflict with adolescents' psychological needs can result in disengagement from learning and further undermine academic and emotional functioning (Wang \& Eccles, 2012b).

\section{Associations Between Parental Involvement and Academic Achievement in Adolescence}

The parental involvement strategies employed by families - along with their effectiveness on adolescents-may change between the elementary and secondary school years partly because of adolescents' growing needs for autonomy and independence (Hill \& Taylor, 2004). These changes in students' development often coincide with transitions to complex and bureaucratic schools, an increased number of teachers, less welcoming attitudes toward parent involvement by schools, and more pressure on parents to understand course planning and college preparation activities (Gutman \& Midgley, 2000; Hill \& Tyson, 2009). Therefore, some of the involvement strategies that worked in early school years may not be as successful or appropriate in secondary school (Eccles \& Harold, 1996; Hill \& Taylor, 2004).

The results of a recent meta-analysis by Hill and Tyson (2009) clarify how the nature of parental involvement and its effects differ between elementary school and middle school. For example, 
parental monitoring and assistance with homework can be an opportunity to teach academic content and develop positive academic skills among elementary school students; however, in middle school, it was found to be negatively associated with achievement. This may be because homework help conflicts with adolescents' sense of efficacy and with the expectations of secondary school coursework (Patall, Cooper, \& Robinson, 2008). In the Hill and Tyson study, academic socialization was found to have the strongest positive relation with student academic achievement; involvement at school and certain types of involvement at home (e.g., the provision of enriching materials and activities) were also associated with higher achievement among middle school students, although less so than academic socialization. However, very few empirical studies simultaneously feature parental involvement in education as a multifaceted construct and investigate its differential effects on achievement in the high school setting. To extract the unique contribution of each parent involvement strategy, we conceptualized parental involvement as: attending school events and volunteering in school (a form of school-based involvement), provision of structure and resources for homework and after-school time (a form of home-based involvement), and communicating parental expectations for education and making preparations and plans for the future (a form of academic socialization).

\section{Associations Between Parental Involvement and Depression in Adolescence}

Less attention in the literature has been devoted to the impact that parental involvement in education might have on adolescent mental health, especially regarding the increasingly acknowledged problem of adolescent depression. Adolescents with depressive symptoms are at increased risk for diminished academic functioning and impairment in educational attainment (Stoep, Weiss, Kuo, Cheney, \& Cohen, 2003). However, there have not been specific studies examining the link between parental involvement in education and adolescent depression. Existing research indicates that when parents involve themselves in the educational context, they become actors in influencing their children's emotional functioning (Pomerantz et al., 2007). The transitions to middle school and high school can be very emotionally demanding events that coincide with adolescents' conflicting desires for autonomy and supportiveness from parents (Eccles et al., 1993). Parenting practices that reduce emotional distress may protect adolescents from further anxiety, facilitate a smoother school transition, and encourage academic motivation among students (Newman, Newman, Griffen, O'Connor, \& Spas, 2007; Pomerantz \& Rudolph, 2003).

Some forms of parental involvement, including positive interactions with school and supportive parent-adolescent communication at home, have been linked with students' improved self-esteem, emotional self-regulation skills, and self-perceptions of academic competence, which could protect adolescents against depressive symptoms (Bean, Barber, \& Crane, 2006; Flouri \& Buchanan, 2003; Shumow \& Lomax, 2002). Parents who keep track of their children's school performance and convey the importance of education may also contribute to the happiness and psychological well-being experienced by their adolescent children and reduce their emotional distress (Grolnick, Kurowski, Dunlap, \& Hevey, 2000). Parental involvement in the form of academic socialization, in particular, allows parents to demonstrate their concern for their children's well-being and openly communicate with them, while also providing a scaffold for adolescents' growing independence (Hill \& Tyson, 2009). In addition, parental involvement may promote positive interpersonal relationships at school through modeling a healthy parent-child relationship and otherwise contributing to children's emotional development (Chen \& Gregory, 2009; Pomerantz et al., 2007; Shumow \& Lomax, 2002). Given the repercussions of depression on adolescent academic and emotional functioning (Wang, 2009), it is critical that we advance our understanding of the role parental involvement in education may play in mitigating the development of depressive symptoms.

\section{Academic Engagement as a Mediator Between Parental Involvement and Youth Outcomes}

Active engagement in high school equips adolescents with learning skills, academic competencies, and educational values that contribute to a successful transition into adulthood (Anguiano, 2004; Wang \& Holcombe, 2010). The extent to which adolescents are behaviorally and emotionally engaged with school shapes how they deal with difficulties and obstacles in school, bounce back from setbacks and failures, and reengage with challenging academic tasks (Skinner et al., 2009; Wang \& Eccles, 2013). In recent studies, students have been found to be more academically engaged when their parents were more involved in their education (Cheung \& Pomerantz, 2011; Simons-Morton \& Crump, 
2003), and this has been particularly true when that involvement took the form of academic socialization, namely, through high parental encouragement and expression of the importance of education (Chen \& Gregory, 2009; Fan \& Williams, 2010).

The role that parental involvement plays in indirectly influencing youth academic and psychological functioning through youth school engagement is theoretically compelling, but not yet tested. According to self-system theory, parents create environments that can support or undermine youth's experiences of themselves as being competent to succeed, connected to others in school, and being autonomous learners (Connell \& Wellborn, 1991; Skinner \& Wellborn, 1994). These experiences influence adolescent engagement in educational activities, which in turn shapes academic and emotional development (Skinner et al., 2009). For example, children of parents whose involvement is characterized by warmth and age-appropriate guidance (e.g., encouragement of educational goals) have greater behavioral engagement, which may act as a positive asset to promote academic success and emotional well-being (Wang \& Eccles, 2012a; Wang \& Huguley, 2012). Similarly, parents who utilize proactive strategies in managing educational activities may encourage children to adopt the same active mentality toward their schoolwork and thereby increase their emotional engagement (Grolnick \& Slowiaczek, 1994). Finally, children may become more academically and psychologically confident because their involved parents have already familiarized them with general school tasks (Grolnick, Price, Beiswenger, \& Sauck, 2007). As such, the effects of parent involvement on youth achievement and depression may be mediated by patterns of student engagement in school.

\section{Differences in Ethnicity and SES}

Recent studies show that the nature and influences of parental involvement on student outcomes may vary across ethnic backgrounds (Hong \& Ho, 2005; Rowley, Kurtz-Costes, \& Cooper, 2010). Deeply rooted cultural beliefs regarding the role of the family in education, the meaning and goals of education, and the diversity of parents' experiences with schools may explain the ethnic variations in parenting approaches and family-school relations (Hill \& Torres, 2010). In general, European American parents are more likely to be involved at school than African American parents, who may place a greater emphasis on home-based involvement strategies (Eccles \& Harold, 1996). It has been suggested that the negative historical experiences of African Americans with the U.S. school system (e.g., legislated discrimination) may contribute to tense and unproductive parent-school relations, render trust and collaboration difficult, and make parental involvement in the school setting less likely (Cross, 2003). While few studies have assessed the impacts of different parental involvement strategies by ethnicity, there are indications that students' outcomes do vary depending on parents' behaviors. For instance, authoritative and autonomy-supportive parenting, which is consistent with the approaches of academic socialization, has been shown to have a stronger effect on the achievement of European American students than African American students (Dornbusch, Ritter, Liederman, Roberts, \& Fraleigh, 1987; Perna \& Titus, 2005).

The effectiveness of parental involvement may also vary across SES. Several studies have suggested that lower income parents tend to be less involved in their children's education (Hill \& Taylor, 2004). Despite holding equally as high aspirations for their children as higher SES parents, parents of a low SES may feel and be less effective at changing school achievement and behavior through their involvement in children's schooling (Chavkin \& Williams, 1989; Hill et al., 2004). These parents may not have the time, resources, or information to facilitate greater involvement and may be hesitant in their interactions with schools because of a perceived lack of competence (Jordan \& Plank, 2000). By contrast, well-educated, higher SES parents may be more informed about opportunities and resources for their children, experience fewer barriers to their involvement, perceive greater effectiveness, and consequently be more involved in their children's education (Lareau, 1996).

Most extant parental involvement studies have been primarily conducted with samples of European American and middle-class families, and some scholars claim that the educational views of these two populations shape the dominant norm for family-school relations (e.g., Hill, 2001; Lareau, 2003). As a result, these views are the ones promoted within schools and assumed to be shared by parents from all backgrounds (Hill et al., 2004). European American and middle-class parents typically have greater experience and representation within the educational system (Lareau, 2003) and therefore may be more confident and skilled at navigating family-school interactions. Such an advantage would contribute to greater success by European American and middle-class parents in terms of their ability to successfully maneuver their 
children through the educational system. However, solely relying on studies that link elevated school involvement to improved achievement among European American and middle-class students fails to acknowledge that not all parents have equal skills, resources, comfort levels, or the cultural willingness to be involved in their children's education within the actual school setting. Calls for greater parental involvement using "proven" strategies must first be assessed for their relevance to parents of different ethnic and socioeconomic groups. It is thus important to consider demographic backgrounds as potential moderators when examining associations between parental involvement and adolescent outcomes.

\section{The Current Study}

Drawing on self-system theory, we aimed to examine the longitudinal associations among parental involvement, academic engagement, achievement, and depression (see Figure 1). Specifically, we investigated to what extent the three types of parental involvement in the fall of 10th grade were related to achievement and depression in the spring of 11th grade. In addition, we examined whether behavioral and emotional engagement in the spring of 10th grade mediated the association between parental involvement in the fall of 10th grade and adolescent achievement and depression in the spring of 11th grade. Finally, we examined whether the associations among parental involvement, academic engagement, and adolescent outcomes varied by ethnicity (i.e., European American vs. African American) and family SES. We hypothesized that parental involvement was positively associated with achievement and negatively with depression, although the associations would vary depending on the type of parental involvement and adolescent outcomes. For instance, academic socialization might have the most potential to fulfill

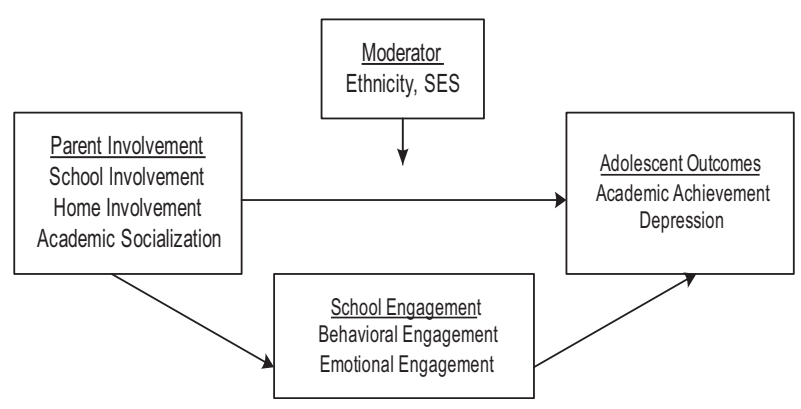

Figure 1. Conceptual model. adolescents' psychological needs in academic settings, whereas home-based and school-based involvement could increase connectedness to parents. In addition, we hypothesized that parental involvement would promote adolescent achievement and reduce depression by enhancing student behavioral and emotional engagement in school based on the mediational model we derived from self-system theory. Finally, we hypothesized that the associations between parental involvement and adolescent outcomes would vary by ethnic background and family SES, although similarities might also exist. For instance, we expected that African American parents would have less school-based involvement than European American parents, but that both ethnic groups would benefit from schoolbased involvement similarly.

\section{Method}

\section{Sample and Procedures}

Study participants in the sample were part of a multiwave longitudinal study designed to increase understanding of the influences of sociocultural context on academic and psychological development during adolescence. Participants were from 10 public high schools within a large, socioeconomically diverse city in the United States. The racial composition of the schools was approximately $66 \%$ European American students, 26\% African American students, and $8 \%$ other racial minority students. This study examines three waves of data: Wave 1 $(N=1,056)$ collected in the fall of 10th grade, Wave $2(N=1,052)$ collected in the spring of 10th grade, and Wave $3(N=935)$ collected in the spring of 11 th grade. Of these respondents, approximately 53\% were European American, 40\% were African American, and $7 \%$ were either biracial or other ethnic minorities. Approximately $49 \%$ of the students were females. The sample had a normally distributed range of socioeconomic levels, with a mean pretax family annual income of $\$ 35,000$, and $71 \%$ of families reported the employment of at least one parent. Forty-one percent of students had at least one parent with a college degree.

The 10 high schools were chosen for convenience, and all 10th graders were eligible for the study. From a pool of 1,282 tenth graders in the 10 high schools, 1,056 adolescents received parental consent to participate (an $82 \%$ consent rate) and were included in Wave 1. At Wave 2 of data collection, the sample comprised 1,052 adolescents of the 1,056 total participating 10th graders $(99 \%$ retention 
rate). At Wave 3 of collection, the sample comprised 935 adolescents of the 1,056 total participating 10th graders (89\% retention rate). Both Waves 2 and 3 retained more than $89 \%$ of the original sample from Wave 1. The most common source of attrition was relocation outside of the school districts. To examine whether sample attrition influenced results, we compared individuals with complete data or missing data at one wave with individuals with missing data at two or more waves on all indicators included in the analyses. None of the 42 comparisons was statistically significant. We dealt with the missing data through full information maximum likelihood estimation, allowing us to include all available data and identify the parameter values with the highest probability of producing the sample data (Baraldi \& Enders, 2010).

The sample was based on parent willingness to participate and on a stratified sampling procedure designed to capture proportional representation of families from each of the 10 high schools. Students were recruited through letters to their families. Those families interested in participating in the study were asked to sign and return a consent form. The investigators used a mixture of surveys, survey interviews, and school records to collect the data. Surveys with students were conducted at school during each wave of the study. Telephone interviews were conducted with the parents during the 10th-grade year. The survey took approximately $30 \mathrm{~min}$ to complete, and the telephone interview also lasted about $30 \mathrm{~min}$. Participating students were offered $\$ 20$ at each wave of data collection, and parents were offered $\$ 40$.

\section{Measures}

Parental involvement. In the 10th grade, we assessed three latent constructs of parental involvement by multiple-item indicators from parent report measures: home-based involvement, schoolbased involvement, and academic socialization. Multiple items represented each of these latent constructs. The Home-Based Involvement Scale included five items assessing the extent to which parents structure after-school time for study and provide enriching materials and events (e.g., "During the school year, how often do you have a set time for your child to do homework?" and "How often do you take your child to visit museum or libraries?"). The School-Based Involvement Scale included five items assessing the extent to which parents attend school events and volunteer at school (e.g., "Thinking back to the last school year, how often did you or your spouse attend a parent-teacher conference?" and "How often did you or your spouse help out at school by doing things like going to school performances, assisting on field trips, helping with fundraising?"). The Academic Socialization Scale included five items assessing the extent to which parents communicate educational goals, values, and aspirations and discuss plans for the future with their children (e.g., "How often do you tell your child that getting good grades is important for getting ahead in life?" and "How often do you discuss plans for college entrance exams?"). Items within these scales were rated on a 5-point scale, ranging from 1 (never) to 5 (very often). The three scales demonstrated good reliability $(\alpha=.75-.82)$ in this study.

Academic engagement. In the 9th and 10th grades, we assessed two latent constructs of academic engagement by multiple-item indicators from student report measures: behavioral and emotional engagement. The behavioral engagement construct was measured by five items from the Behavioral Engagement Scale (Connell \& Wellborn, 1991). Sample items included "How often have you gotten schoolwork done on time?" and "How often have you skipped class?" Item responses were rated along a 5-point scale, ranging from 1 (almost never) to 5 (almost always). Some item responses were reverse coded so that higher scores indicated higher levels of behavioral engagement ( $\alpha \mathrm{s}=.79-.84$ ). The construct of emotional engagement refers to student feelings of interest, enjoyment, and value of the school learning and was assessed by five items from the School Emotional Engagement Scale ( $\alpha \mathrm{S}=.85-.87)$ adapted from Gottfredson's (1984) Effective School Battery. Sample items were "I enjoy learning at school" and "I feel interested in learning new things in school." The item responses ranged from 1 (strongly disagree) to 5 (strongly agree). These scales have been shown to be both reliable and valid in prior research, demonstrating internal consistency, convergent and divergent validity, and measurement invariance across gender, ethnicity, and SES (Wang, Willett, \& Eccles, 2011).

Academic achievement. In the 10th and 11th grades, student academic grade point average (GPA) was collected from school report cards at the end of each school year. GPA was an average of students' grades in the core academic subjects (English, math, science, and social sciences). A weighted average was computed such that $\mathrm{A}=5, \mathrm{~B}=4, \mathrm{C}=3, \mathrm{D}=2$, and $\mathrm{F}=1$. The grading system was the same across schools. 
Depression. In the 10th and 11th grades, students responded to survey questions that were related to depressive symptoms during the past month. Depressive symptoms consisted of a subset of 20 items from the Children's Depression Inventory (Kovacs, 1992). Possible responses ranged from 1 (no symptomatology) to 3 (high symptomatology; as $=.89$ and .88). We created a latent construct of adolescent depression by 20 item indicators.

Covariates. We included student gender $(0=$ female, $1=$ male $)$, ethnicity $(0=$ African American, $1=$ European American), SES, prior student academic achievement, depression, and problem behaviors measured in fall of 10th grade in the models. Each of these variables has been associated with parental involvement indicators and with academic engagement in prior studies (Johnson, Crosnoe, \& Elder, 2001; Wang \& Eccles, 2012a). SES was measured using a composite of annual family income and parents' highest education. Family income indicates the social and educational resources available to a student, whereas parental education generally remains stable over the course of a student's childhood (Sirin, 2005). Both of these measures are robust predictors of parenting practices and parental knowledge of the education system (Hill \& Tyson, 2009; Hoff, Laursen, \& Tardif, 2002). Parents answered whether they had received a college degree or not $(0=$ no college degree, $1=$ college degree). Parents also rated their "total household income," which included both mothers' and fathers' income, according to the following scale: $1=\$ 15,000$ or less, $2=\$ 15,001-\$ 25,000,3=\$ 25,001-\$ 35,000,4=$ $\$ 35,001-\$ 50,000, \quad 5=\$ 50,001-\$ 75,000, \quad 6=\$ 75$, $001-\$ 100,000,7=\$ 100,001-\$ 150,000$, and $8=$ over $\$ 150,000$. We standardized and averaged the parents' education and family income to create the SES composite score $(r=.82)$.

We also kept in mind that adolescence is often a period of exploration and risk taking (Wang, 2009) and that youth sometimes experiment with alcohol and drugs. These underlying problem behaviors may be driving lower academic achievement, not parental involvement. For instance, parents may be setting rules around homework and grades because students have a difficult time focusing, or they may be interacting with the school in response to behavioral problems. Therefore, it is important to control for prior problem behavior differences among students. Student problem behaviors were assessed in the fall of 10th grade through self-reports on five items based on the work of Elliott, Huizinga, and Menard (1989). Example items were "In the past year, how often have you been disobedient in school?" and "How often have you been involved in a gang fight?" The response format ranged from 1 (never) to 5 (10 or more times).

\section{Analytic Strategies}

We used structural equation modeling (SEM) with Mplus 6.1 (Muthen \& Muthen, Los Angeles, $\mathrm{CA})$ to fit the hypothesized relations among the study constructs. The nested nature of our data (students nested in schools) was accounted for by fitting a multilevel model with random effects and producing correctly adjusted standard errors in the model estimations. To address the research questions, we began by fitting baseline models that assessed the direct effects of the three types of parental involvement on academic achievement and depression. After establishing these direct associations, we introduced the two types of academic engagement into the path model and tested their mediating effect on the association between parental involvement and achievement and depression. To test for mediation, we estimated indirect effects with delta method standard errors to confirm the mediation effects (MacKinnon, Lockwood, Hoffman, West, \& Sheets, 2002). Finally, to examine the moderation effect of ethnicity and SES, we used a stepwise process for the multigroup comparisons in SEM to examine whether the measurement and structural relations in the final model varied by ethnicity and SES. We included a series of increasingly restrictive constraints on the model parameters and examined whether doing so led to a significant decrease in the model fit by using the chi-square difference test. If the impositions led to a significant decrease in overall model fit, it would indicate that there were differences across the groups in the pattern of associations.

\section{Results}

Means, standard deviations, and bivariate correlations among the key variables are shown in Table 1. The mean for each type of parental involvement suggested that, overall, parents showed more home-based involvement and academic socialization than school-based involvement at 10th grade. African American parents reported more home-based involvement (African American $=3.79, \quad$ European $\quad$ American $=3.65)$, $t(1,055)=3.47, \quad p<.001$, and less school-based involvement (African American $=1.56$, European American $=2.28), \quad t(1,055)=21.45, \quad p<.001, \quad$ than 
Table 1

Means, Standard Deviations, and Intercorrelations Among All Latent Variables $(\mathrm{N}=1,056)$

\begin{tabular}{|c|c|c|c|c|c|c|c|c|c|c|}
\hline Variable & 1 & 2 & 3 & 4 & 5 & 6 & 7 & 8 & 9 & 10 \\
\hline 1. School involvement & 1.00 & & & & & & & & & \\
\hline 2. Home involvement & .07 & 1.00 & & & & & & & & \\
\hline 3. Academic socialization & $.16^{* *}$ & $.14^{* * *}$ & 1.00 & & & & & & & \\
\hline 4. Behavioral engagement & .06 & $.19^{* * *}$ & $.27^{* * *}$ & 1.00 & & & & & & \\
\hline 5. Emotional engagement & $.18^{* *}$ & .04 & $.31^{* * *}$ & $.35^{* * *}$ & 1.00 & & & & & \\
\hline 6. Grade point average & -.06 & $.20^{* * *}$ & $.23^{* * *}$ & $.38^{* * *}$ & $.20^{* * *}$ & 1.00 & & & & \\
\hline 7. Depression & $-.22^{* * *}$ & -.05 & $-.28^{* * *}$ & $-.16^{* *}$ & $-.36^{* * *}$ & $-.21^{* *}$ & 1.00 & & & \\
\hline 8. Male & $.07^{*}$ & .04 & .05 & $-.25^{* * *}$ & $-.09^{* *}$ & $-.19^{* * *}$ & .04 & 1.00 & & \\
\hline 9. Socioeconomic status & $.14^{* * *}$ & $.19^{* * *}$ & $.22^{* * *}$ & $.12^{*}$ & $.17^{* * *}$ & $.15^{* * *}$ & $-.10^{*}$ & .04 & 1.00 & \\
\hline 10. White & $.21^{* * *}$ & $-.09 *$ & .04 & $.20^{* * *}$ & $-.14^{* *}$ & $.21^{* * *}$ & -.02 & .03 & -.01 & 1.00 \\
\hline$M$ & 1.92 & 3.73 & 3.42 & 4.54 & 3.78 & 3.23 & 1.86 & 0.51 & 0.62 & 0.55 \\
\hline$S D$ & 0.57 & 0.93 & 1.19 & 0.89 & 0.67 & 0.75 & 0.50 & 0.50 & 0.39 & 0.23 \\
\hline
\end{tabular}

$* p<.05 . * * p .01 . * * p<.001$.

European American parents. No ethnic differences in academic socialization were found. Higher SES parents reported more home-based involvement $(r=.14)$, school-based involvement $(r=.19)$, and academic socialization $(r=.22)$ than lower SES parents.

All variables had low to moderate correlations (from .07 to .38), suggesting little multicollinearity (Kline, 2005). Confirmatory factor analysis verified that the hypothesized latent constructs measure discrete, single latent variables. The standardized loadings ranged from .40 to .81 and were all statistically significant at the .05 level. All the latent constructs, including three parental involvement variables, two academic engagement variables, one achievement variable, and one depression variable, were measured by multiple observed individual item indicators. For the assessment of the measurement model, all the latent variables were allowed to intercorrelate simultaneously. The measurement model provided adequate fit, $\chi^{2}(42, N=1,056)=713.24$, $p<.001$, comparative fit index $(\mathrm{CFI})=.99$, standardized root mean square error $(\mathrm{SRMR})=.01$, and root mean square error of approximation $($ RMSEA $)=.01$.

\section{Direct Effects of Parental Involvement on Achievement and Depression}

We examined the direct association between parental involvement and adolescent achievement and depression (see Figure 2). The overall model fit was good, $\chi^{2}(35, N=1,056)=654.54, p<.001$, $\mathrm{CFI}=.98$, SRMR $=.02$, RMSEA $=.02$. The modification indices suggest no significant cross-loadings. Home-based involvement and academic socialization were positively associated with academic achievement $(\gamma \mathrm{s}=.13$ and .17 , respectively), whereas schoolbased involvement was not associated with academic achievement. School-based involvement and academic socialization were negatively associated with depression $(\gamma \mathrm{s}=-.15$ and -.19 , respectively), whereas home-based involvement was not associated with depression. Overall, the model accounts for $30 \%$ of the variance in academic achievement and $27 \%$ of the variance in depression.

\section{Mediation Effects of Academic Engagement}

The mediation analyses examined the extent to which student behavioral and emotional engagement mediated the associations between parental involvement and achievement and depression (see Figure 3). The fit of this mediation model is adequate, $\quad \chi^{2}(55, \quad N=1,056)=788.30, \quad p<.001$, $\mathrm{CFI}=.97, \mathrm{SRMR}=.03$, RMSEA $=.02$. Table 2 presents the results of direct, indirect, and total effects in the final model. Home-based involvement and academic socialization were positively associated with behavioral engagement $(\gamma \mathrm{s}=.16$ and .19 , respectively), whereas school-based involvement and academic socialization were positively associated with emotional engagement $(\gamma \mathrm{s}=.13$ and .22 , respectively). Moreover, the association between home-based involvement and achievement was partially mediated by behavioral engagement, and the association between academic socialization and achievement was partially mediated by behavioral and emotional engagement. The associations between school-based involvement and academic socialization and depression were partially mediated by emotional engagement. Taken 


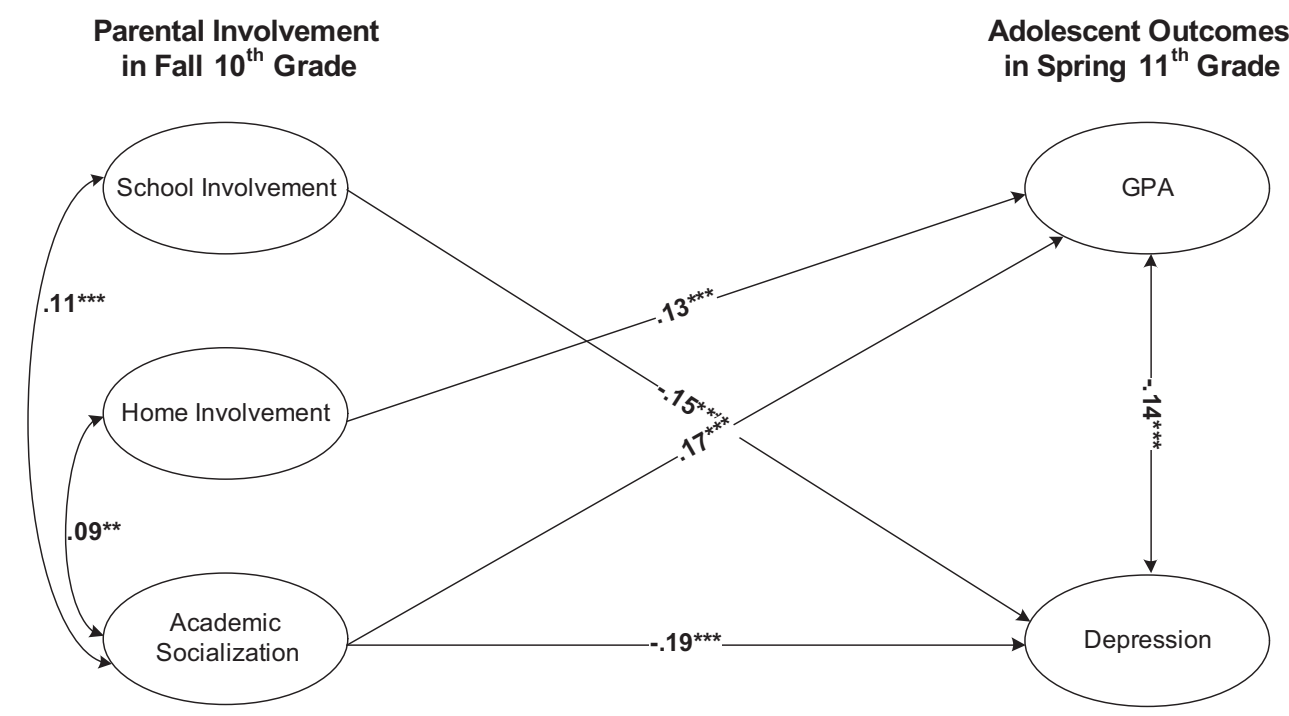

Figure 2. Path model depicting direct effort of parental involvement on achievement and depression, controlling for prior academic engagement, grade point average, depression, behavioral problems, and demographic characteristics. All coefficients shown are standardized and statistically significant. ${ }^{*} p<.05 .{ }^{* *} p<.01 .{ }^{* * *} p<.001$.

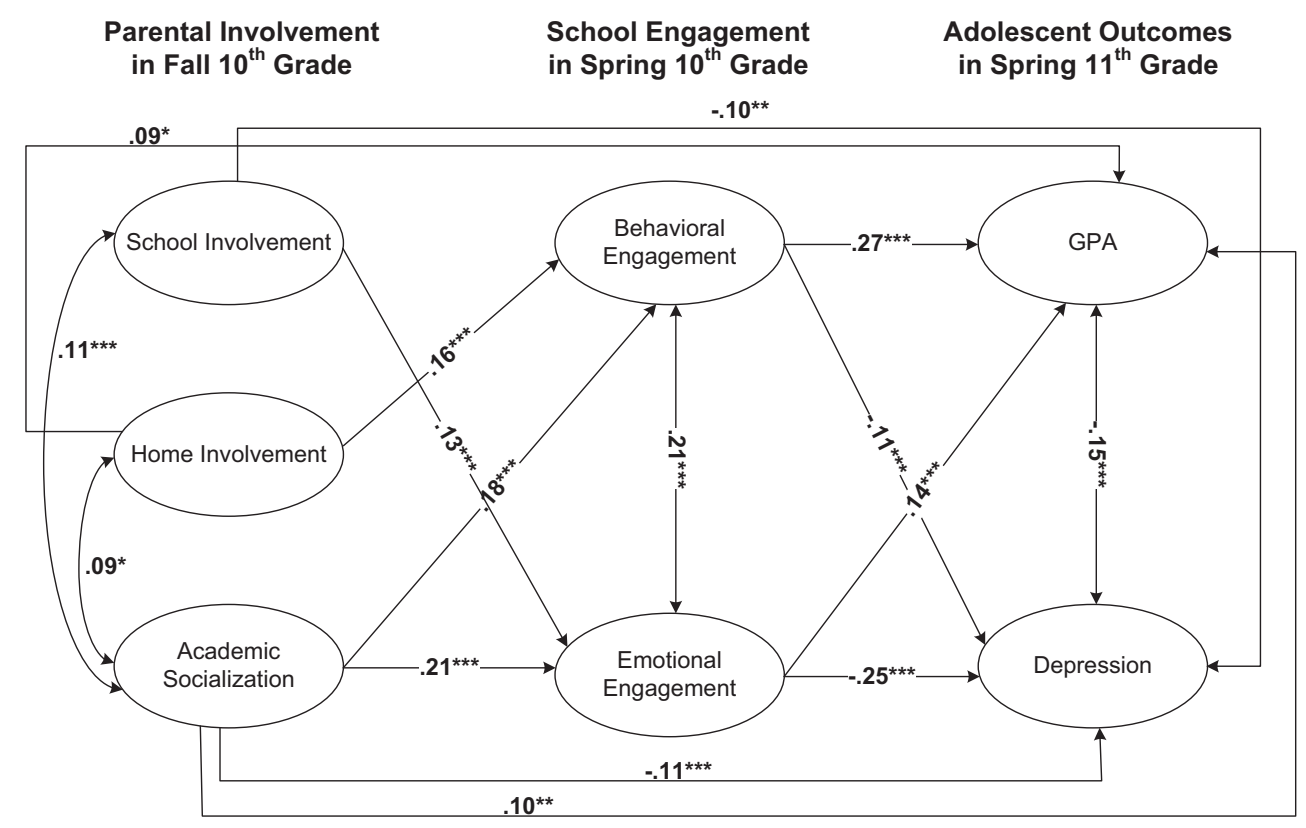

Figure 3. Final model depicting mediation effort of academic engagement between parental involvement and achievement and depression, controlling for prior academic engagement, grade point average, depression, behavioral problems, and demographic characteristics. All coefficients shown are standardized and statistically significant.

$* p<.05 . * * p .01 . * * * p<.001$.

together, academic socialization influenced achievement indirectly through both behavioral and emotional engagement in school. Academic socialization and school-based involvement influenced depression directly and also indirectly through emotional engagement in school. Home-based involvement influenced academic achievement directly and indirectly through behavioral engagement. The inclusion of the mediating variables adds $13 \%$ and $10 \%$ to the explained variance in academic achievement and depression, respectively. Overall, the variables explain $43 \%$ and $37 \%$ of the variance in academic achievement and depression, respectively. 
Table 2

Standardized Direct, Indirect, and Total Effects for the Final Model From Parental Involvement to Achievement and Depression

\begin{tabular}{|c|c|c|c|c|c|c|}
\hline \multirow[b]{2}{*}{ Predictor and covariate } & \multicolumn{3}{|c|}{ GPA at 11 th grade } & \multicolumn{3}{|c|}{ Depression at 11 th grade } \\
\hline & Direct & Indirect & Total & Direct & Indirect & Total \\
\hline \multicolumn{7}{|l|}{ Predictor variable } \\
\hline School involvement & -.03 & .04 & .01 & $-.10^{* *}$ & $-.05^{*}$ & $-.15^{* * *}$ \\
\hline Home involvement & $.09^{* *}$ & $.07^{* *}$ & $.16^{* * *}$ & -.01 & -.03 & -.04 \\
\hline Academic socialization & $.10^{* *}$ & $.14^{* * *}$ & $.24^{* * *}$ & $-.11^{* * *}$ & $-.10^{* *}$ & $-.21^{* * *}$ \\
\hline \multicolumn{7}{|l|}{ Covariate } \\
\hline GPA at 10 th grade & $.24^{* * *}$ & - & - & $-.12^{* *}$ & - & - \\
\hline Depression at 10 th grade & $-.10^{* *}$ & - & - & $.20^{* * *}$ & - & - \\
\hline Problem behavior at 10 th grade & $-.23^{* * *}$ & - & - & $.16^{* * *}$ & & \\
\hline Male & $-.12^{* * *}$ & - & - & .02 & - & - \\
\hline SES & $.12^{* * *}$ & & & $-.06^{*}$ & & \\
\hline White & $.15^{* * *}$ & - & - & .03 & - & - \\
\hline
\end{tabular}

Note GPA = grade point average; $\mathrm{SES}=$ socioeconomic status.

$* p<.05 . * * p .01 . * * p<.001$.

\section{Moderation Effect of Ethnicity and SES}

We first conducted the moderation analyses to determine whether the measurement and structural relations in the final model varied across two ethnic groups: European American and African American students. The measurement part of the model was first tested by constraining the factor loadings of the two groups to be equal. The $\Delta \chi^{2}$ difference test showed that model fit decrease is not significant across ethnicity, $\Delta \chi^{2}(12, N=1,056)=14.35$, ns. The constrained measurement model provides a good model fit overall for the two groups, respectively. After examining measurement equivalence, the paths of the two groups were constrained to be equal sequentially. Moderation analyses by ethnicity revealed no significant differences in the structural relations and suggest the generality of the overall model across European American and African American students.

For moderation analysis involving SES, we divided the sample into high-, moderate-, and lowSES groups. The high-SES group included students who had an SES 0.25 SD above the mean $(n=514)$. The low-SES group included students who had an SES $0.25 S D$ below the mean $(n=375)$. The moderate-SES group included students who had an SES within $0.25 S D$ of the mean $(n=167)$. We removed the moderate-SES group and ran the multigroup analysis between high- and low-SES groups to ensure that the two groups were significantly different in the mean SES, $t(889)=23.57, p<.001$. The high-SES group had greater school-based involvement, home-based involvement, and academic socialization than the low-SES group. The measure- ment part of the model was first tested by constraining the factor loadings of the two models to be equal, and the $\Delta \chi^{2}$ difference test showed that model fit decrease is not significant across SES, $\Delta \chi^{2}(12$, $N=889)=17.38$, ns. The constrained measurement model provides a good model fit overall for the two groups. The examination of path equivalence indicated significant differences across SES groups in the associations between home-based involvement and behavioral engagement, as well as academic socialization and emotional engagement. Homebased involvement was more strongly associated with behavioral engagement for the low-SES group $(\beta=.23, p<.001)$ than for the high-SES group $(\beta=.15, p<.001)$. Academic socialization was also more strongly associated with emotional engagement for the low-SES group $(\beta=.29, p<.001)$ than for the high-SES group $(\beta=.20, p<.001)$.

\section{Discussion}

In this study we conceptualized parental involvement in education as a multidimensional construct (i.e., school involvement, home involvement, and academic socialization) and examined the associations of each of these elements with adolescent achievement and depression in high school. This study contributes to the literature by identifying which types of parental involvement are most effective for high school students and the mechanisms through which these types operate. We found that parental involvement in 10th grade improved not only academic but also emotional functioning among adolescents in 11th grade. However, the 
effects of parental involvement on achievement and depression varied by the type of involvement in which parents engaged. For instance, among the types of parental involvement, academic socialization had the strongest positive relation with achievement and strongest negative relation with depression. In addition, we extended past research on the application of self-system theory to identify the processes by which different parental involvement strategies influence adolescent achievement and depression. Specifically, parent involvement in education predicted student academic success and mental health both directly and indirectly through behavioral and emotional engagement. Finally, the examination of moderation effect of ethnicity and SES contributes to our understanding that the effects of parental involvement on adolescent outcomes did not differ for ethnicity, but did differ for SES.

The association between academic socialization and achievement was mediated by student behavioral and emotional engagement. In other words, parents who conveyed the importance and value of education and discussed future plans with their children motivated them to engage in their academic work behaviorally and emotionally. In turn, this behavioral and emotional engagement in school led to higher achievement. Furthermore, the provision of appropriate structure and an intellectually supportive home environment was found to have a positive association with achievement through behavioral engagement.

On the other hand, this study indicates that simply requiring parents to spend time at school (i.e., volunteering) may not result in achievement gains among high school students. One possible explanation of this is that parents come to school or attend parent-teacher conferences for a variety of reasons, including dealing with nonacademic issues (e.g., behavior management). Thus, school-based involvement may not directly relate to student academic performance. Another possible explanation is that the involvement opportunities available to parents in high school are typically restricted to administrative or extracurricular duties. The hectic nature of high schools containing multiple teachers have made it difficult to accommodate parents in the classroom (Hill \& Tyson, 2009). Adolescents may also be uncomfortable with their parents visiting school, as their presence conflicts with their desire for autonomy (Deslandes \& Cloutier, 2002). Thus, parents' access to information about actual academic content may be limited, possibly making school-based efforts less effective in improving achievement than other types of parental involvement during high school (Collins \& Laursen, 2004; Grolnick et al., 2000). Interestingly, the parents in our sample reported less school-based involvement in their children's education than they did for home-based or academic socialization activities. It is possible that these lower levels of school-based involvement during high school indicate parents' recognition of schools' and adolescents' attitudes toward their involvement and the lack of opportunities to increase their engagement within this setting.

However, although attending parent-teacher conferences and volunteering at school appear to have no direct effect on achievement in high school, our findings show that there are still emotional benefits to students whose parents are involved in school activities. Indeed, there is evidence that the affective nature of parental school-based involvement supports adolescent mental health (Pomerantz, Ng, \& Wang, 2006; Pomerantz, Wang, \& Ng, 2005). It is plausible that parents who are actively involved in their children's school activities convey the message that they place greater importance and value on their children's school progress and overall well-being (Grolnick \& Slowiaczek, 1994). Thus, despite adolescents' self-sufficient attitude, when parents simply attend school events or volunteer at school, for example, they may provide adolescents with a sense of caring, support, and connection to their parents. While parents must remain mindful not to encroach on students' feelings of independence, the tangible activities of school-based involvement may help adolescents in establishing emotional closeness with parents, which can help the student construct positive representations of self (Barrett, Shortt, \& Healy, 2002).

These findings also demonstrate that academic socialization not only positively impacts adolescent academic achievement but also mental health in high school. This type of parental involvement represents strategies that are appropriate for both the high school structure and adolescent developmental needs by providing adolescents with confidence in their abilities to succeed and opportunities to fulfill their personal identities. Such emotional and psychological support in turn fosters these students' behavioral and emotional engagement in school (Wang \& Eccles, 2012b). In particular, the use of academic socialization strategies by parents emphasizes the significance and value of education, leading children to personally appreciate the worth of their time in school (Hill \& Taylor, 2004). This internalization could be another factor in 
stimulating their engagement in school and driving high academic achievement. In addition, parent involvement through academic socialization may provide students with an effective coping strategy for dealing with challenges that school presents (Pomerantz et al., 2006). Research indicates that by discussing future educational plans with children, parents model a coping mechanism in which they take control of the situation-a technique that creates positive changes in mental health (Grolnick \& Slowiaczek, 1994). This type of lesson in active coping strategy could lead to lower levels of depressive symptoms, possibly through increasing adolescents' academic self-efficacy and reducing any sense of learned helplessness (Baird, Scott, Dearing, \& Hamill, 2009).

Consistent with prior studies (Eccles \& Harold, 1996; Hill \& Chao, 2009), we found some evidence of ethnic differences in home-based and schoolbased involvement. While European American parents reported more frequent school involvement than African American parents, African American parents tended to be more involved in their children's education from home than European American parents. The finding that African American parents in our study reported relatively low involvement within the school setting seems to support Hill and Taylor's (2004) argument that cultural beliefs and negative historical experiences with the public school system may deter African American parents from being involved in school. In addition, European American parents may feel more comfortable with being involved in school because of their generally high representation within the educational system, their knowledge of how it operates (Lareau, 2003), and their perceptions of social expectations to do so. However, even though the mean levels of home and school involvement differed between European American and African American parents, the strengths of the longitudinal associations among parent involvement, academic engagement, and adolescent achievement and depression were similar across these two ethnic groups. Overall, these results encouragingly suggest that the effects of each type of parental involvement on adolescents identified in this study can be applied to both ethnic groups, although European American and African American parents may have different approaches to engaging in their children's education.

SES was also significant in determining the nature of parental involvement and its effects on student engagement. Lower SES parents were found to be less involved in their adolescents' education than high-SES parents through school-based, home- based, and academic socialization strategies. This could be the result of limited resources and information about how to most effectively engage with their high school students (Lareau, 1996). Psychological stressors such as working long hours and financial struggles may also interfere with low-SES parents' ability to engage with their children using the behaviors known to promote high achievement motivation and performance. Importantly, however, when low-SES parents did employ home-based involvement strategies, their adolescents were more strongly behaviorally engaged in school than their high-SES counterparts. The reason for this could possibly stem from the fact that lower SES families tend to live in high-risk environments. By providing a structured, enriching atmosphere at home, lower SES parents may protect against negative environmental distractions and instill in their children a level of self-discipline and orientations toward learning (Gutman, Sameroff, \& Eccles, 2002). In addition, academic socialization was found to be more strongly related to emotional engagement among lower SES students than among higher SES students. Adolescents growing up in disadvantaged communities may have less exposure to information about college or positive educational role models, making it especially important for their parents to convey the value of education and discuss plans to fulfill future goals. Such conversations can help adolescents feel that their time spent at school is meaningful and stimulate more positive attitudes toward education, which may lead to improved achievement in the future.

\section{Limitations, Strengths, and Implications}

Some limitations of our study should be noted. Our study mainly asked parents how often they exhibited specific behaviors and did not measure the quality of these interactions. Reliance on frequency alone may not tell us the full story (Pomerantz et al., 2007). Future studies could benefit from measures of parental involvement that are based on quality in addition to frequency. While the distinction between quality and quantity is important (see Pomerantz et al., 2007), it is necessary to bear in mind that quality and quantity are not entirely independent of each other-what is initially a positive parental behavior may become negative as its frequency goes up and results in nagging. Similarly, this study relies mainly on self-report surveys from students to assess school engagement, potentially raising concerns about the influence of social desirability on their responses. 
Future studies should use multiple sources of information and multiple methodologies to gain a more comprehensive perspective on school engagement. Another area that could benefit from future research is the effect of longitudinal and continual parental involvement. This study examined parental involvement at only one grade, but to fully understand the effects of parental involvement, it is necessary to examine a much longer time period so that the changing nature of involvement can be examined. The effect of parental involvement may be very different if parents have been consistently involved rather than if they only begin to engage during high school. Results from studies examining this question could impact how and when parental involvement programs are initiated.

Furthermore, our focus on only two racial categories within this study may limit the generalizability of our conclusions to other ethnic groups, specifically adolescents of Asian or Hispanic descent. For example, there is some evidence that in Asian American populations where cultural expectations to achieve are high and parental control is more acceptable, academic socialization may not be as effective relative to other practices and to other ethnic groups (e.g., Wang, Pomerantz, \& Chen, 2007). Parental academic socialization could be perceived as undue pressure to achieve and may increase depression and anxiety in Asian American students. Among Mexican American immigrant families, DelgadoGaitan (1994) found a willingness to support children's education through multiple forms of parental involvement. However, the cultural value of consejos, which emphasizes communication, warmth, familial expectations, and the encouragement of independent thinking among children, may mean that academic socialization practices could exert a greater effect on Mexican American adolescents' academic and psychological well-being. Future research should investigate whether our findings could be generalized to adolescents of other ethnic groups.

Finally, GPA is only one of many indicators of academic achievement. It is plausible that the findings regarding the effects of parental involvement and student engagement might be different if different measures of academic achievement and success (e.g., standardized test scores, school dropout, graduation, and attendance) were used. Indeed, recent studies suggest that student behavioral and emotional engagement is more strongly associated with high school dropout and graduation than GPA (Wang \& Eccles, 2012b). Future research should investigate whether the choice of academic achievement measures affects the findings.
The chaotic nature and prevalence of negative academic and social behaviors in high school, combined with the evolving needs of adolescence, can lead to poor academic performance and elevated rates of depression among students (Eccles et al., 1993; Wang, 2009). The results of this study indicate that parents can and should maintain appropriate involvement in their adolescents' education. The multifaceted nature of parental involvement captured in this study has enabled us to examine which parental involvement strategies foster or undermine adolescent academic success and mental health and to better understand the mechanisms through which parental involvement influences adolescent outcomes. As we expected, the association between parental involvement and adolescent outcomes varies across the different types of parent involvement. It is critical to keep such relational distinctions in mind when studying parental involvement: Not all parental involvement strategies impact the different types of adolescent outcomes in the same manner. The acquired knowledge will have the potential to contribute to the design of more specifically targeted and nuanced parent involvement programs. Furthermore, this study identifies the role that academic engagement plays in mediating the relation between various types of parental involvement and adolescent achievement and depression. Parental involvement can promote positive adolescent development by motivating students to be behaviorally and emotionally engaged in school. Although prior research points to the educational benefits of parent involvement, we have found that appropriate parent involvement in high school also provides protection against depression. Although we know that parents play an important role in forming adolescent development academically and emotionally (Spera, 2005), study of their direct effect on school engagement and the indirect effect that they have on youth academic achievement and depression is an important extension of existing work.

Education occurs in a broad social context, and many important educational decisions are increasingly made outside of the school building. The pivotal role that parents can play in their children's learning must therefore be considered. Current policies and regulations, such as the No Child Left Behind Act, mandate schools to increase parental involvement, but provide little information on how to do so. It is imperative to understand what constitutes appropriate involvement so that practical strategies can be incorporated into policies and programs that assist parents in being a positive, 
active influence on their children's education and development. While we know that it is important for parents to remain involved in their children's education even during high school, parents should be made aware of the impacts different involvement behaviors can have on their children's academic and emotional functioning. Academic socialization has consistently been shown to be the most effective parental involvement approach, but its use can be restricted by parents' limited access to resources and to knowledge about positive and constructive techniques. Schools may be able to play an important role in this process by providing all parents with access to resources that support academic socialization, such as information about college fairs and how to prepare for college entrance exams. It is also important for schools to recognize the special circumstances faced by many lower SES parents, particularly their work schedules, and to make sure that resources are readily available to these parents as well. This could be an opportunity for schools and families to cooperate and to reinforce each other's contributions to student achievement and positive mental health.

\section{References}

Anguiano, R. P. (2004). Families and schools: The effect of parental involvement on high school completion. Journal of Family Issues, 25, 61-85. doi:10.1177/ 0192513X03256805

Baird, G. L., Scott, W. D., Dearing, E., \& Hamill, S. K. (2009). Cognitive self-regulation in youth with and without learning disabilities: Academic self-efficacy, theories of intelligence, learning vs. performance goal preferences, and effort attributions. Journal of Social and Clinical Psychology, 28, 881-908. doi:10.1521/jscp.2009. 28.7.881

Baraldi, A. N., \& Enders, C. K. (2010). An introduction to modern missing data analyses. Journal of School Psychology, 48, 5-37. doi:10.1016/j.jsp.2009.10.001

Barrett, P., Shortt, A., \& Healy, L. (2002). Do parent and child behaviors differentiate families whose children have obsessive-compulsive disorder from other clinic and non-clinic families? Journal of Child Psychology and Psychiatry, 43, 597-607. doi:10.1111/1469-7610.00049

Bean, R. A., Barber, B. K., \& Crane, D. R. (2006). Parental support, behavioral control, and psychological control among African American youth. Journal of Family Issues, 27, 1335-1355. doi:10.1177/0192513X06289649

Chavkin, N. F., \& Williams, D. L. (1989). Low-income parents' attitudes toward parent involvement in education. Journal of Sociology E Social Welfare, 16, 17-28.

Chen, W., \& Gregory, A. (2009). Parental involvement as a protective factor during the transition to high school.
Journal of Educational Research, 103, 53-62. doi:10.1080/ 00220670903231250

Cheung, C. S., \& Pomerantz, E. M. (2011). Parents' involvement in children's learning in the United States and China: Implications for children's academic and emotional adjustment. Child Development, 82, 932-950. doi:10.1111/j.1467-8624.2011.01582.x

Collins, W. A., \& Laursen, B. (2004). Changing relationships, changing youth: Interpersonal contexts of adolescent development. Journal of Early Adolescence, 24, 55-62. doi:10.1177/0272431603260882

Connell, J. P., \& Wellborn, J. G. (1991). Competence, autonomy, and relatedness: A motivational analysis of self-system processes. In M. R. Gunnar \& L. Sroufe (Eds.), Self processes and development (pp. 43-77). Hillsdale, NJ: Erlbaum.

Cross, W. E. (2003). Tracing the historical origins of youth delinquency and violence: Myths and realities about Black culture. Journal of Social Issues, 59, 67-82. doi:10. 1111/1540-4560.t01-1-00005

Delgado-Gaitan, C. (1994). Consejos: The power of cultural narratives. Anthropology E Education Quarterly, 25, 298-316.

Deslandes, R., \& Cloutier, R. (2002). Adolescents' perception of parental involvement in schooling. School Psychology International, 23, 220-232. doi:10.1177/ 0143034302023002919

Dornbusch, S., Ritter, P., Liederman, P., Roberts, D., \& Fraleigh, M. (1987). The relation of parenting style to adolescent school performance. Child Development, 58, 1244-1257. doi:10.2307/1130618

Duchesne, S., Ratelle, C. F., Poitras, S., \& Drouin, E. (2009). Early adolescent attachment to parents, emotional problems, and teacher-academic worries about the middle school transition. Journal of Early Adolescence, 29, 743-766. doi:10.1177/0272431608325502

Eccles, J. S., \& Harold, R. D. (1996). Family involvement in children's and adolescents' schooling. In A. Booth \& J. F. Dunn (Eds.), Family-school links: How do they affect educational outcomes? (pp. 3-34). Mahwah, NJ: Erlbaum.

Eccles, J. S., Midgley, C., Wigfield, A., Buchanan, C. M., Reuman, D., Flanagan, C., et al. (1993). Development during adolescence: The impact of stage-environment fit on young adolescents' experiences in schools and in families. American Psychologist, 48, 90-101. doi:10.1037/ 0003-066X.48.2.90

Elliott, D. S., Huizinga, D., \& Menard, S. (1989). Multiple problem youth: Delinquency, substance use, and mental health problems. New York: Springer-Verlag.

Epstein, J. L., \& Sanders, M. G. (2002). Family, school, and community partnerships. In M. H. Bornstein (Ed.), Handbook of parenting: Vol. 5. Practical issues in parenting (pp. 407-437). Mahwah, NJ: Erlbaum.

Fan, X., \& Chen, M. (2001). Parental involvement and students' academic achievement: A meta-analysis. Educational Psychology Review, 13, 1-22. doi:10.1023/ A:1009048817385 
Fan, W., \& Williams, C. (2010). The effects of parental involvement on students' academic self-efficacy, engagement and intrinsic motivation. Educational Psychology, 30, 53-74. doi:10.1080/01443410903353302

Flouri, E., \& Buchanan, A. (2003). The role of father involvement and mother involvement in adolescents' psychological well-being. British Journal of Social Work, 33, 399-406. doi:10.1093/bjsw/33.3.399

Gottfredson, G. D. (1984). The Effective School Battery: User's manual. Odessa, FL: Psychological Assessment Resources.

Grolnick, W. S., Kurowski, C. O., Dunlap, K. G., \& Hevey, C. (2000). Parental resources and the transition to junior high. Journal of Research on Adolescence, 10, 465-488. doi:10.1207/SJRA1004_05

Grolnick, W. S., Price, C. E., Beiswenger, K. L., \& Sauck, C. C. (2007). Evaluative pressure in mothers: Effects of situation, maternal, and child characteristics on autonomy supportive versus controlling behavior. Developmental Psychology, 43, 991-1002. doi:10.1037/0012-1649.43.4.991

Grolnick, W. S., \& Slowiaczek, M. L. (1994). Parents' involvement in children's schooling: A multidimensional conceptualization and motivational model. Child Development, 65, 237-252. doi:10.2307/1131378

Gutman, L. M., \& Midgley, C. (2000). The role of protective factors in supporting the academic achievement of poor African American students during the middle school transition. Journal of Youth and Adolescence, 20, 223-248. doi:10.1023/A:1005108700243

Gutman, L. M., Sameroff, A. S., \& Eccles, J. S. (2002). The academic achievement of African American students during early adolescence: An examination of risk, promotive, and protective factors. American Journal of Community Psychology, 30, 367-399. doi:10.1023/ A:1015389103911

Hill, N. E. (2001). Parenting and academic socialization as they relate to school readiness: The role of ethnicity and family income. Journal of Educational Psychology, 93, 686-697. doi:10.1037/0022-0663.93.4.686

Hill, N. E., Castellino, D. R., Lansford, J. E., Nowlin, P., Dodge, K. A., Bates, J. E., et al. (2004). Parent academic involvement as related to school behavior, achievement, and aspirations: Demographic variations across adolescence. Child Development, 75, 1491-1509. doi: 10.1111/j.1467-8624.2004.00753.x

Hill, N. E., \& Chao, R. K. (2009). Families, schools, and the adolescent: Connecting research, policy, and practice. New York: Teachers College Press.

Hill, N. E., \& Taylor, L. C. (2004). Parental school involvement and children's academic achievement. Current Directions in Psychological Science, 13, 161-164. doi:10.1111/j.0963-7214.2004.00298.x

Hill, N. E., \& Torres, K. (2010). Negotiating the American dream: The paradox of aspirations and achievement among Latino students and engagement between their families and schools. Journal of Social Issues, 66, 95-112. doi:10.1111/j.1540-4560.2009.01635.x

Hill, N. E., \& Tyson, D. F. (2009). Parental involvement in middle school: A meta-analytic assessment of the strat- egies that promote achievement. Developmental Psychology, 45, 740-763. doi:10.1037/a0015362

Hoff, E., Laursen, B., \& Tardif, T. (2002). Socioeconomic status and parenting. In M. H. Bornstein (Ed.), Handbook of parenting (2nd ed., pp. 231-252). Mahwah, NJ: Erlbaum.

Hong, S., \& Ho, H. (2005). Direct and indirect longitudinal effects of parental involvement on student achievement: Second-order latent growth modeling across ethnic groups. Journal of Educational Psychology, 97, 32-42. doi:10.1037/0022-0663.97.1.32

Jeynes, W. H. (2009). The relationship between parental involvement and urban secondary school student academic achievement: A meta-analysis. Urban Education, 42, 82-110. doi:10.1177/0042085906293818

Johnson, M. K., Crosnoe, R., \& Elder, G. H., Jr. (2001). Students' attachment and academic engagement: The role of race and ethnicity. Sociology of Education, 74, 318-340.

Jordan, W. J., \& Plank, S. B. (2000). Talent loss among high-achieving poor students. In M. G. Sanders (Ed.), Schooling students placed at risk: Research policy and practice in the education of poor and minority adolescents (pp. 83-108). Mahwah, NJ: Erlbaum.

Kline, R. B. (2005). Principles and practice of structural equation modeling (2nd ed.). New York: Guilford Press.

Kovacs, M. (1992). Children's Depression Inventory manual. North Tonawanda, NY: Multi-Health Systems.

Lareau, A. (1996). Assessing parent involvement in schooling: A critical analysis. In A. Booth \& J. F. Dunn (Eds.), Family-school links: How do they affect educational outcomes? (pp. 57-64). Mahwah, NJ: Erlbaum.

Lareau, A. (2003). Unequal childhoods: Class, race, and family life. Berkeley: University of California Press.

Li, Y., \& Lerner, R. M. (2011). Trajectories of school engagement during adolescence: Implications for grades, depression, delinquency, and substance use. Developmental Psychology, 47, 233-247. doi:10.1037/ a0021307

MacKinnon, D. P., Lockwood, C. M., Hoffman, J. M., West, S. G., \& Sheets, V. (2002). A comparison of methods to test mediation and other intervening variable effects. Psychological Methods, 7, 83-104. doi:10.1037/ 1082-989X.7.1.83

Masten, A. S., Roisman, G. I., Long, J. D., Burt, K. B., Obradovic, J., Riley, J. R., et al. (2005). Developmental cascades: Linking academic achievement and externalizing and internalizing symptoms over 20 years. Developmental Psychology, 41, 733-746. doi:10.1037/0012-1649.41.5.733

Newman, B. M., Newman, P. R., Griffen, S., O'Connor, K., \& Spas, J. (2007). The relationship of social support to depressive symptoms during the transition to high school. Adolescence, 42, 441-459.

Patall, E. A., Cooper, H., \& Robinson, J. C. (2008). Parent involvement in homework: A research synthesis. Review of Educational Research, 78, 1039-1101. doi:10.3102/ 0034654308325185

Perna, L. W., \& Titus, M. A. (2005). The relationship between parental involvement as social capital and 
college enrollment: An examination of racial/ethnic group differences. Journal of Higher Education, 76, 485-518.

Pomerantz, E. M., Moorman, E. A., \& Litwack, S. D. (2007). The how, whom, and why of parents' involvement in children's academic lives: More is not always better. Review of Educational Research, 77, 373-410. doi:10.3102/003465430305567

Pomerantz, E. M., Ng, F., \& Wang, Q. (2006). Mothers' mastery-oriented involvement in children's homework: Implications for the well-being of children with negative perceptions of competence. Journal of Educational Psychology, 98, 99-111. doi:10.1037/0022-0663.98.1.99

Pomerantz, E. M., \& Rudolph, K. D. (2003). What ensues from emotional distress? Implications for competence estimates. Child Development, 74, 329-346. doi:10.1111/ 1467-8624.7402001

Pomerantz, E. M., Wang, Q., \& Ng, F. (2005). Mothers' affect in the homework context: The importance of staying positive. Developmental Psychology, 41, 414-427. doi:10.1037/0012-1649.41.2.414

Roeser, R. W., \& Eccles, J. S. (2000). Schooling and mental health. In A. J. Sameroff, M. Lewis, \& S. M. Miller (Eds.), Handbook of developmental psychopathology (2nd ed., pp. 135-156). Dordrecht, the Netherlands: Kluwer Academic.

Rowley, S. J., Kurtz-Costes, B., \& Cooper, S. (2010). Schooling and the development of African American children. In J. Meece \& J. Eccles (Eds.), Handbook of research on schools, schooling, and human development (pp. 275-292). Hillsdale, NJ: Erlbaum.

Ryan, R. M., \& Deci, E. L. (2000). Self-determination theory and the facilitation of intrinsic motivation, social development, and well-being. American Psychologist, 55, 68-74. doi:10.1037/0003-066X.55.1.68

Seginer, R. (2006). Parents' educational involvement: A developmental ecology perspective. Parenting: Science and Practice, 6, 1-48. doi:10.1207/s15327922par0601_1

Shumow, L., \& Lomax, R. (2002). Parental efficacy: Predictor of parenting behavior and adolescent outcomes. Parenting: Science and Practice, 2, 127-150. doi:10.1207/ S15327922PAR0202_03

Simons-Morton, B. G., \& Crump, A. D. (2003). Association of parental involvement and social competence with school adjustment and engagement among sixth graders. Journal of School Health, 73, 121-126. doi:10. 1111/j.1746-1561.2003.tb03586.x

Sirin, S. (2005). Socioeconomic status and academic achievement: A meta-analytic review of research. Review of Educational Research, 75, 417-453. doi:10.3102/ 00346543075003417

Skinner, E. A., Kindermann, T. A., Connell, J. P., \& Wellborn, J. G. (2009). Engagement and disaffection as an organizational construct in the dynamics of motivational development. In K. R. Wentzel \& A. Wigfield (Eds.), Handbook of motivation in school (pp. 223-246). Mahwah, NJ: Erlbaum.

Skinner, E. A., \& Wellborn, J. G. (1994). Coping during childhood and adolescence: A motivational perspective.
In D. Featherman, R. Lerner, \& M. Perlmutter (Eds.), Life-span development and behavior (pp. 91-133). Hillsdale, NJ: Erlbaum.

Spera, C. (2005). A review of the relationship among parenting practices, parenting styles, and adolescent school achievement. Educational Psychology Review, 17, 125-146. doi:10.1007/s10648-005-3950-1

Stoep, A. V., Weiss, N. S., Kuo, E. S., Cheney, D., \& Cohen, P. (2003). What proportion of failure to complete secondary school in the US population is attributable to adolescent psychiatric disorder? Journal of Behavioral Health Services $\mathcal{E}$ Research, 30, 119-124. doi:10.1007/BF02287817

Wang, M. T. (2009). School climate support for behavioral and psychological adjustment: Testing the mediating effect of social competence. School Psychology Quarterly, 24, 240-251. doi:10.1037/a0017999

Wang, M. T., Brinkworth, M. B., \& Eccles, J. S. (2013). The moderation effect of teacher-student relationship on the association between adolescents' self-regulation ability, family conflict, and developmental problems. Developmental Psychology, 49, 690-705. doi:10.1037/ a0027916

Wang, M. T., \& Eccles, J. S. (2012a). Social support matters: Longitudinal effects of social support on three dimensions of school engagement from middle to high school. Child Development, 83, 877-895. doi:10.1111/j. 1467-8624.2012.01745.x

Wang, M. T., \& Eccles, J. S. (2012b). Adolescent behavioral, emotional, and cognitive engagement trajectories in school and their differential relations to educational success. Journal of Research on Adolescence, 22, 31-39. doi:10.1111/j.1532-7795.2011.00753.x

Wang, M. T., \& Eccles, J. S. (2013). School context, achievement motivation, and academic engagement: A longitudinal study of school engagement using a multidimensional perspective. Learning and Instruction, 28, 12-23.

Wang, M. T., \& Holcombe, R. (2010). Adolescents' perceptions of school environment, engagement, and academic achievement in middle school. American Educational Research Journal, 47, 633-662. doi:10.3102/ 0002831209361209

Wang, M. T., \& Huguley, J. P. (2012). Parental socialization as a moderator of the effects of racial discrimination on educational success among African American adolescents. Child Development, 83, 1716-1731. doi:10. $1111 /$ j.1467-8624.2012.01808.x

Wang, M. T., Willett, J. B., \& Eccles, J. S. (2011). The assessment of school engagement: Examining dimensionality and measurement invariance across gender and race/ethnicity. Journal of School Psychology, 49, 465-480. doi:10.1016/j.jsp.2011.04.001

Wang, Q., Pomerantz, E. M., \& Chen, H. (2007). The role of parents' control in early adolescents' psychological functioning: A longitudinal investigation in the United States and China. Child Development, 78, 1592-1610. doi:10.1111/j.1467-8624.2007.01085.x 